\title{
Main Results of Phase IV BEMUSE Project: Simulation of LBLOCA in an NPP
}

\author{
M. Pérez, ${ }^{1}$ F. Reventós, ${ }^{1}$ L. Batet, ${ }^{1}$ R. Pericas, ${ }^{1}$ I. Toth, ${ }^{2}$ P. Bazin, ${ }^{3}$ A. de Crécy, ${ }^{3}$ \\ P. Germain, ${ }^{3}$ S. Borisov, ${ }^{4}$ H. Glaeser, ${ }^{5}$ T. Skorek, ${ }^{5}$ J. Joucla, ${ }^{6}$ P. Probst, ${ }^{6}$ A. Ui, ${ }^{7}$ B. Chung, ${ }^{8}$ \\ D. Y. Oh, ${ }^{9}$ M. Kyncl, ${ }^{10}$ R. Pernica, ${ }^{10}$ A. Manera, ${ }^{11}$ F. D'Auria, ${ }^{12}$ A. Petruzzi, ${ }^{12}$ and A. Del Nevo ${ }^{12}$ \\ ${ }^{1}$ Technical University of Catalonia (UPC), Diagonal 647, 08028 Barcelona, Spain \\ ${ }^{2}$ Atomic Energy Research Institute, Hungary \\ ${ }^{3}$ Commissariat à l'Energie Atomique, France \\ ${ }^{4}$ EDO Guidropress, Russia \\ ${ }^{5}$ Gesellschaft für Anlagen- und Reaktorsicherheit, Germany \\ ${ }^{6}$ Institut de Radioprotection et de Sûreté Nucléaire, France \\ ${ }^{7} J a p a n$ Nuclear Energy Safety, Japan \\ ${ }^{8}$ Korea Atomic Energy Research Institute, South Korea \\ ${ }^{9}$ Korean Institute of Nuclear Safety, South Korea \\ ${ }^{10}$ Nuclear Research Institute, Czech Republic \\ ${ }^{11}$ Paul Scherrer Institute, Switzerland \\ ${ }^{12}$ University of Pisa, Italy
}

Correspondence should be addressed to F. Reventós, francesc.reventos@upc.edu

Received 19 June 2009; Accepted 6 January 2010

Academic Editor: Michel Giot

Copyright ( 2010 M. Pérez et al. This is an open access article distributed under the Creative Commons Attribution License, which permits unrestricted use, distribution, and reproduction in any medium, provided the original work is properly cited.

\begin{abstract}
Phase IV of BEMUSE Program is a necessary step for a subsequent uncertainty analysis. It includes the simulation of the reference scenario and a sensitivity study. The scenario is a LBLOCA and the reference plant is Zion 1 NPP, a 4 loop PWR unit. Thirteen participants coming from ten different countries have taken part in the exercise. The BEMUSE (Best Estimate Methods plus Uncertainty and Sensitivity Evaluation) Program has been promoted by the Working Group on Accident Management and Analysis (WGAMA) and endorsed by the Committee on the Safety of Nuclear Installations (CSNI). The paper presents the results of the calculations performed by participants and emphasizes its usefulness for future uncertainty evaluation, to be performed in next phase. The objectives of the activity are basically to simulate the LBLOCA reproducing the phenomena associated to the scenario and also to build a common, well-known, basis for the future comparison of uncertainty evaluation results among different methodologies and codes. The sensitivity calculations performed by participants are also presented. They allow studying the influence of different parameters such as material properties or initial and boundary conditions, upon the behaviour of the most relevant parameters related to the scenario.
\end{abstract}

\section{Introduction}

Models and codes are an approximation of the real physical behaviour occurring during a hypothetical transient, and the data used to build these models are also known with certain accuracy. Therefore, code predictions areuncertain. The BEMUSE programme is focussed on the application of uncertainty methodologies to large break LOCAs. This introduction deals with some background considerations and establishes the objectives of the programme along with its steps and phases.

1.1. Background. One of the goals of computer code models of Nuclear Power Plants (NPP) is to demonstrate that these are designed to respond safely at postulated accidents. To deal with uncertainties, the analyses can either use conservative or best-estimate (BE) codes. 
(i) The conservative codes contain assumptions to try to cover unknown uncertainties. These assumptions are often unphysical and lead to predictions that could be worse than reality.

(ii) $\mathrm{BE}$ codes are designed to model all the relevant processes in a physically realistic manner. A calculation with a $\mathrm{BE}$ code is then considered the best approach of what is more likely to occur. In any case, it is necessary to evaluate the uncertainty of the estimation.

The reasons and motivation for using $\mathrm{BE}$ codes have been explained in many occasions [1-3]. The OECD BEMUSE started with the aim of achieving a deeper understanding of such methods [4].

1.2. Objectives. The BEMUSE programme is focussed on the application of uncertainty methodologies to large break LOCAs. The objectives of this programme are the following:

(i) to evaluate the practicability, quality, and reliability of best-estimate methods including uncertainty evaluations in applications relevant to nuclear reactor safety,

(ii) to develop common understanding,

(iii) to promote/facilitate their use by the regulator bodies and the industry.

Using the same codes and similar methods should allow comparing the potential important uncertain parameters, and the effects of different modelling for uncertainties can be evaluated. Therefore, the assessment of each methodology by comparison with experimental data is also one of the purposes of the programme.

1.3. Steps and Phases. The BEMUSE program is divided into two steps. The first step is to perform an uncertainty and sensitivity analysis of LOFT L2-5 test calculations and the second is to perform this analysis for an NPP-LBLOCA.

Each of these two steps is made up of three phases.

(i) First step (Phases I, II, and III):

(a) Phase I: presentation a priori of the uncertainty evaluation methodology to be used (lead organisation: IRSN),

(b) Phase II: reanalysis of the ISP-13 exercise, post-test of LOFT L2-5 test (lead organisation: University of Pisa),

(c) Phase III: uncertainty evaluation of the L2-5 test calculations (lead organisation: CEA).

(ii) Second step (Phases IV, V, and VI):

(a) Phase IV: best-estimate analysis of an NPPLBLOCA (lead organisation: UPC),

(b) Phase V: uncertainty evaluation of the NPPLBLOCA (lead organisation: UPC),

(c) Phase VI: status report, conclusions, and recommendations (lead organisation: GRS).

\section{Lessons Learned from Previous Phases}

Participants to Phase II achieved significant results. Almost all performed calculations appear qualified against the fixed criteria and few mismatches between results and acceptability thresholds have been characterized. Dispersion bands of results appear substantially less than years ago in ISP13. Modelling techniques used by participants are the most fruitful outcome of phase II to be used in phase IV analysis.

The Input/Output Specification of Phase IV has been prepared by the coordinator team taking into account achievements and recommendations basically of Phase II but also of phases I and III.

\section{Phase IV Scope and Objectives}

The scope of Phase IV of BEMUSE programme is the simulation of an LB-LOCA in a Nuclear Power Plant using experience gained in previous Phase II [5]. Calculation results will be the basis for uncertainty evaluation, to be performed in next phase.

The objectives of the activity are

(i) to simulate an LB-LOCA reproducing the phenomena associated to the scenario,

(ii) to have a common, well-documented basis for the execution of the uncertainty evaluation step in Phase V.

\section{Plant and Scenario}

The selected plant was Zion Station, a dual-reactor nuclear power plant operated and owned by the Commonwealth Edison network. No other options were available. This power generating station is located in the extreme eastern portion of the city of Zion, Lake County, Illinois. It is approximately 40 direct-line miles north of Chicago, Illinois and 42 miles south of Milwaukee, Wisconsin.

The main features of the plant are

(i) 4 loops,

(ii) pressurized water reactor,

(iii) westinghouse design,

(iv) net Output: 1040 MWe,

(v) thermal power $3250 \mathrm{MWth}$,

(vi) permanently shut down,

(vii) date started: June 1973,

(viii) date closed: January 1998.

The Steady-State conditions are summarized in Table 1

The scenario is a cold leg Large Break LOCA in double guillotine without HPIS. The following statements specify the scenario description:

(i) LPIS injection with a pressure set point of $1.42 \mathrm{MPa}$ (driven by a flow-pressure table),

(ii) accumulators injection with a pressure set point of 4.14 MPa, 
TABLE 1: Steady-State main parameters.

\begin{tabular}{lc}
\hline Parameter & Steady-State value \\
\hline Power $(\mathrm{MW})$ & 3250.0 \\
Pressure in cold leg $(\mathrm{MPa})$ & 15.8 \\
Pressure in hot leg $(\mathrm{MPa})$ & 15.5 \\
Pressurizer level $(\mathrm{m})$ & 8.8 \\
Core outlet temperature $(\mathrm{K})$ & 603.0 \\
Primary coolant flow $(\mathrm{kg} / \mathrm{s})$ & 17357.0 \\
Secondary pressure $(\mathrm{MPa})$ & 6.7 \\
Steam generator's downcomer level $(\mathrm{m})$ & 12.2 \\
Feed water flow per loop $(\mathrm{kg} / \mathrm{s})$ & 439.2 \\
Accumulator pressure $(\mathrm{MPa})$ & 4.14 \\
Accumulator gas volume per tank $\left(\mathrm{m}^{3}\right)$ & 15.1 \\
Accumulator liquid volume per tank $\left(\mathrm{m}^{3}\right)$ & 23.8 \\
Reactor coolant pump's velocity $(\mathrm{rad} / \mathrm{s})$ & 120.06
\end{tabular}

TABLE 2: Time sequence of imposed events.

\begin{tabular}{lc}
\hline Event & Time $(\mathrm{s})$ \\
\hline Break & 0.0 \\
SCRAM & 0.0 \\
Reactor coolant pumps trip & 0.0 \\
Steam line isolation & 10.0 \\
Feed water isolation & 20.0 \\
HPIS & NO \\
\hline
\end{tabular}

(iii) containment pressure imposed as a function of time after the break,

(iv) reactor coolant pumps velocity imposed as a function of time after the break (see Table 2.)

All the information needed to carry out Phase IV calculations was organized by the coordinator as the "BEMUSE Phase IV Input Specification" [5] and distributed among participants. The specification includes information on:

(i) decay power multiplier,

(ii) LPIS pressure-flow curve,

(iii) containment pressure,

(iv) pump velocity for primary coolant pumps in intact loops,

(v) pump velocity for primary coolant pumps in broken loops.

All the available details related to the plant lay-out were also included in the specification.

It is important to point out that, as the plant was in permanently shutdown condition from 1998, no detailed information could be made available if needed during the development of the project. In order to work out this problem along with plant parameters, the main features of the LBLOCA scenario were specified in order to ensure common initial and boundary conditions.

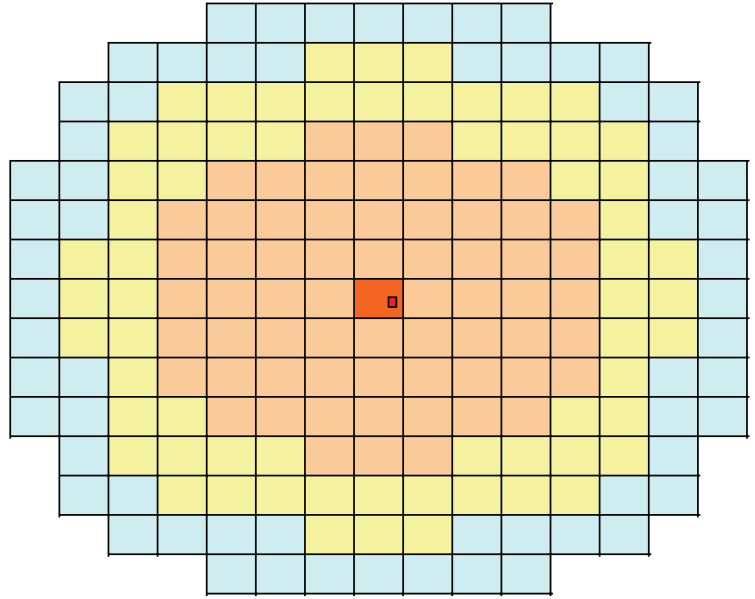

\begin{tabular}{|c|l|l|}
\hline FA & Rods per FA =204 & Fuel rods \\
\hline 64 & Peripheral channel & 13056 \\
\hline 64 & Average channel & 13056 \\
\hline 64 & Hot channel & 13056 \\
\hline 1 & Hot FA in hot channel & 203 \\
\hline 1 Rod & Hot rod in hot FA & 1 \\
\hline 193 & Total & 39372 \\
\hline
\end{tabular}

FIGURE 1: Core heat structures.

\section{Codes and Nodalizations}

Table 3 shows the features of codes and nodalizations used by each participant. The table includes

(i) number of hydraulic nodes,

(ii) number of mesh points for the heat structures,

(iii) number of core channels (not including the bypass channel),

(iv) number of axial core nodes per channel.

Five active heat structures were nodalized simulating the fuel elements. Figure 1 shows a sketch of core heat structures zones, listed below:

Zone 1: average fuel rods in peripheral channels,

Zone 2: average fuel rods in average channels,

Zone 3: average fuel rods in hot channels,

Zone 4: hot fuel assembly in hot channel,

Zone 5: hot rod in hot fuel assembly.

Figures 2 and 3 show the sketch of two different nodalization schemes used by two different participants.

The most relevant differences among the nodalizations used are the core vessel detail and the fuel rods. Core vessels have been modelled using one dimensional and three dimensional codes. In each particular case, the resulting flow distribution, ECCS bypass, and the behaviour of liquid in the upper head, among others, significantly explain the 
TABLE 3: Nodalization resources used by each participant.

\begin{tabular}{|c|c|c|c|c|c|}
\hline Participant & Code's name & $\begin{array}{c}\text { Hydraulic } \\
\text { nodes }\end{array}$ & $\begin{array}{c}\text { Mesh points } \\
\text { (heat structures) }\end{array}$ & $\begin{array}{l}\text { Core channels } \\
\text { (core channels) }\end{array}$ & $\begin{array}{l}\text { Axial active core } \\
\text { nodes per channel }\end{array}$ \\
\hline AEKI & ATHLET 2.0A & 580 & 1839 & 2 & 18 \\
\hline CEA & CATHARE V2.5 1 mod.3.1 & NS & NS & NS & NS \\
\hline EDO & Tech-M-97 & 87 & 811 & 5 & $12(*)$ \\
\hline GRS & ATHLET 2.1A & 395 & 526 & 2 & 18 \\
\hline IRSN & CATHARE2 V2.5_1 mod5.1 & NS & NS & NS & NS \\
\hline JNES & TRACE ver 4.05 & 743 & 10660 & 16 & 42 \\
\hline KAERI & MARS 3.1 & 1116 & NS & 3 & 18 \\
\hline KINS & RELAP5/MOD3.3 & 280 & 2193 & 2 & 18 \\
\hline NRI-1 & RELAP5/MOD3.3 & 306 & 2055 & 4 & 18 \\
\hline PSI & TRACE5.0rc3 & 908 & 5117 & 5 & 18 \\
\hline UNIPI-1 & RELAP/MOD3.2 & NS & NS & NS & NS \\
\hline UNIPI-2 & CATHARE2 V2.5 1 & 79 & 12017 & 5 & 21 \\
\hline UPC & RELAP5/MOD3.3 & 305 & 2193 & 2 & 18 \\
\hline
\end{tabular}

$(*)$ The fuel path is simulated by 10 axial nodes.

diversion of results. Among one-dimensional codes, an influent feature in nodalization is the use or the availability of cross-flow junctions between the core channels and between the downcomer pipes. Related to fuel rods, one participant simulated the oxidation of the cladding while the others did not compute it.

The specifications document for BEMUSE phase IV devoted a whole section [5, Section 3] to list a number of requirements and recommendations for nodalization performance with the aim to have a common basis for comparison. Among them

(i) some initial conditions,

(ii) some nodalization characteristics (core, downcomer, lower plenum, and the break itself),

(iii) the use of code options (reflood and CCFL).

The level at which each participant followed the recommended procedures strongly affects the dispersion of the results.

\section{Main Results}

The nodalization development and the steady-state results were compared among participants in a systematic way. Figure 4 shows a piece of information related to the complete comparison. The example is the normalized pressure drop curve which is quite acceptable. Most of the participants manage to reproduce the reference curve. Some of the differences are due to the small changes performed by participants after the reference curve was supplied. These small changes (like those related to resplitting the downcomer from 2 to 4 pipes in the coordinators case) produced only small deviations in the comparative plot but came up with some improvements in the reference case.

The comparison of participant results for the reference case has also been performed in a systematic way which includes (i) calculated sequence of events,

(ii) time trends,

(iii) relevant Thermalhydraulic Aspects (RTA),

(iv) comments on similarities and discrepancies found among the different groups.

All this information can be found in detail in Phase IV report. Among the 25 compared time trends, the most significant have been selected and are shown below in Figures 5-10. Figure 5 shows time trend of the intact loop 1 pressure in hot leg. A zoom-in figure has been chosen in order to show the cause of the different behaviour observed in accumulators' injection. Although this difference in time is only about 5 or 6 seconds between the most extreme predictions, it helps understanding other important aspects like the differences in accumulators' pressure or in integral break mass flow that appear respectively in Figures 6 and 7.

Most of the events related to the scenario are strongly dependent on primary pressure time trend. Despite of the dispersion shown in some of the Figures, some events are predicted in a consistent way by participants among these:

(i) subcooled blowdown ended,

(ii) cladding temperature initially deviated from saturation (DNB in core),

(iii) pressurizer emptied,

(iv) accumulator injection initiated,

(v) LPIS injection initiated.

Events related to the partial top-down rewet need some explanation. After analyzing the corresponding Figures, despite of a nonnegligible dispersion, the shape of the curves shows some consistency. All participants predict a first PCT, a temperature decrease (at the initiation of the partial rewet), and a further temperature increase (at the end of the partial rewet). These events are not so clearly shown when participants are asked to define a time quantity related to 


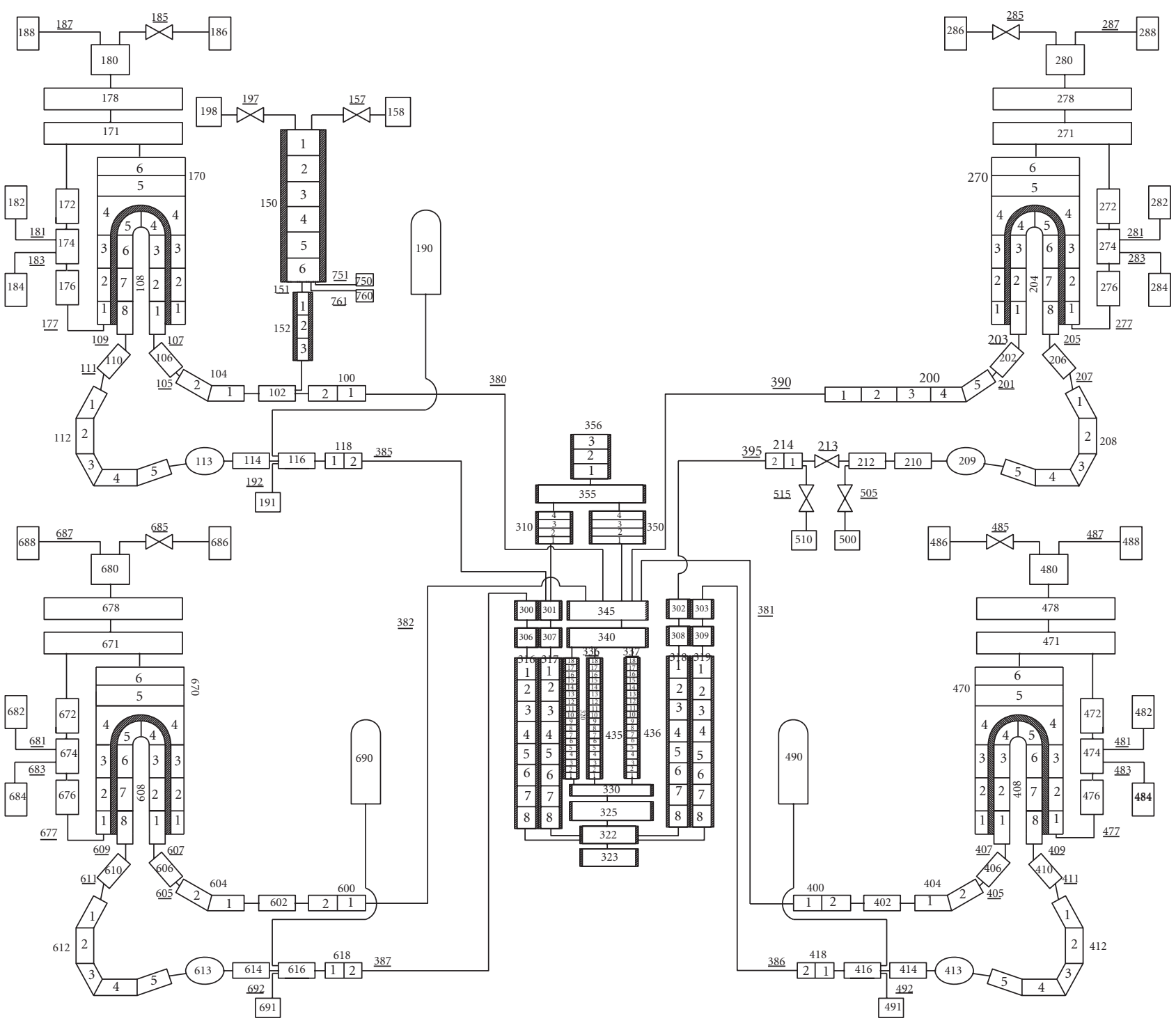

FIgURE 2: Example of 1-D Relap5 nodalization scheme used by UPC.

each event but there is a general agreement on the shape of the curves. Clearly the time trend analysis (instead of the simple comparison of the time of occurrence of the events) is the best way to show the discrepancies and similarities among results.

A similar comment can be made regarding accumulator behaviour. Despite that injection initiation is consistently predicted by participants and properly shown in Figure 8, the prediction of accumulators emptying shows some dispersion. As it is a phenomenon depending on intact leg pressure, pressure error and cumulative time error have a strong effect on the occurrence of the event and dispersion increases.

Finally, the core thermal behaviour, and mainly the full quench, is another event needed of clarification. Figure 10 is maybe the best information for discussion that has some comments involving code effect. The spread of results for the first PCT and for the second is not so high (roughly $200 \mathrm{~K}$ for each peak). The lowest of PCT has been obtained by KAERI
$(1159.1 \mathrm{~K})$ and highest of PCT by EDO "GUIDROPRESS" (1326.15 K). Difference between lowest and highest of PCT for RELAP users is about $100 \mathrm{~K}$, for CATHARE and ATHLET users is about $40 \mathrm{~K}$, and for TRACE users is $20 \mathrm{~K}$. Eight participants predicted the time of PCT between $40 \mathrm{~s}$ and $60 \mathrm{~s}$ except for NRI-1, CEA, GRS, JNES, and IRSN. These participants predicted more early the time of PCT (about $10 \mathrm{~s}$ ). The major differences between results come with the reflooding behaviour and mainly its duration. Concerning this aspect, among the 13 participants, 8 of them show a medium reflood duration (total core quench obtained between 160 and $250 \mathrm{~s}), 3$ other computations show a long reflood duration (total core quench between 320 to $420 \mathrm{~s}$ ), and the other 2 show a kind of slow cladding temperature decrease in which it is difficult to establish the time of full quench.

It is clear that dispersion bands exist but it is also clear that the effort of explaining the reasons of such dispersion is a valuable outcome from this phase. The outcome of BEMUSE 


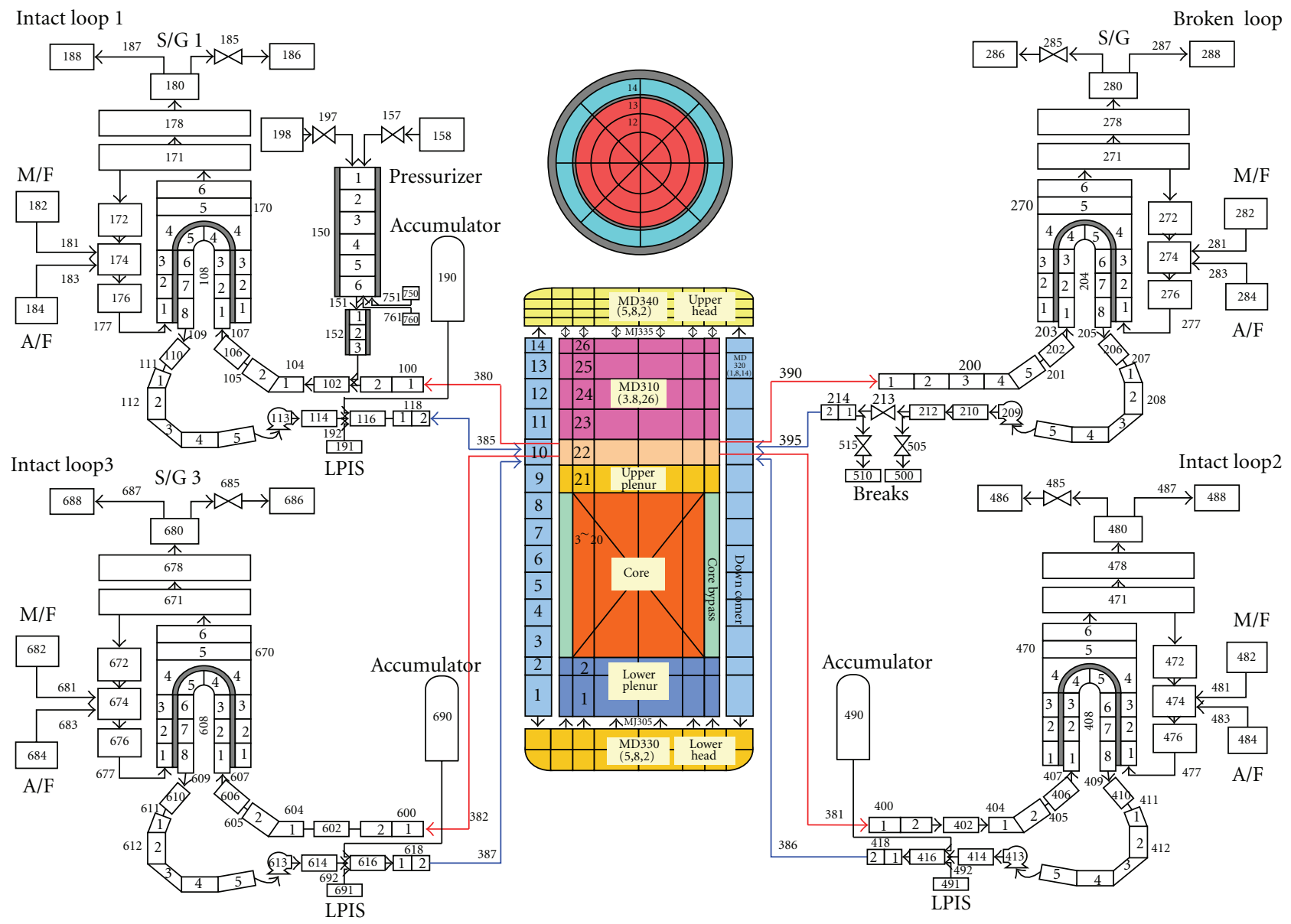

FIGURE 3: Example of 3-D MARS vessel nodalization scheme used by KAERI.

Phase IV is also helpful to understand the nuances existing inside the user effect. The discussion on the point related to the full quench has been useful to clarify the "border" between user effect and code effect. Figure 11 enlights these considerations putting together CATHARE and RELAP5 calculations results for this particular aspect. Despite the consistency of both groups of calculations, some code effect appears. This point is a minor result of Phase IV detected within the programme although it cannot be solved in its framework.

\section{Sensitivity Calculations}

Different sensitivity calculations were performed in Phase IV with the aim of helping to prepare the following Phase $\mathrm{V}$ of BEMUSE project. The results can be used by participants individually either when deciding which parameters are to be included in their respective uncertainty analysis or after running the uncertainty calculations (for those participants using methods based on Wilks' formula) when deciding whether to accept or to put in question the results of the sensitivity analysis postcalculation.

In order to provide the reader with a better sight of the sensitivity analysis results, the values for $\triangle \mathrm{PCT}$ and for $\triangle R E F L O O D$ given by all participants have been averaged. As reasonable ranges of variation have been assumed for the input parameters, $\triangle \mathrm{PCT}$ and $\triangle R E F L O O D$ values provide a good measure of the influence that these input parameters can have on the calculation results.

Figure 12 is devoted to illustrate quantitatively the usefulness of sensitivity results as an example for $\triangle \mathrm{PCT}$. It shows the mean impact on $\triangle \mathrm{PCT}$ in ${ }^{\circ} \mathrm{K}$ when the sensitivity input parameter changes from its lower to its upper value. The Figure includes the standard deviation of the ranges found by participants. For the $\triangle \mathrm{PCT}$, participants in average have found that the most influential parameters are those related to the energy stored in the fuel elements (i.e., fuel and gap conductivity, power-before and after the scram, 


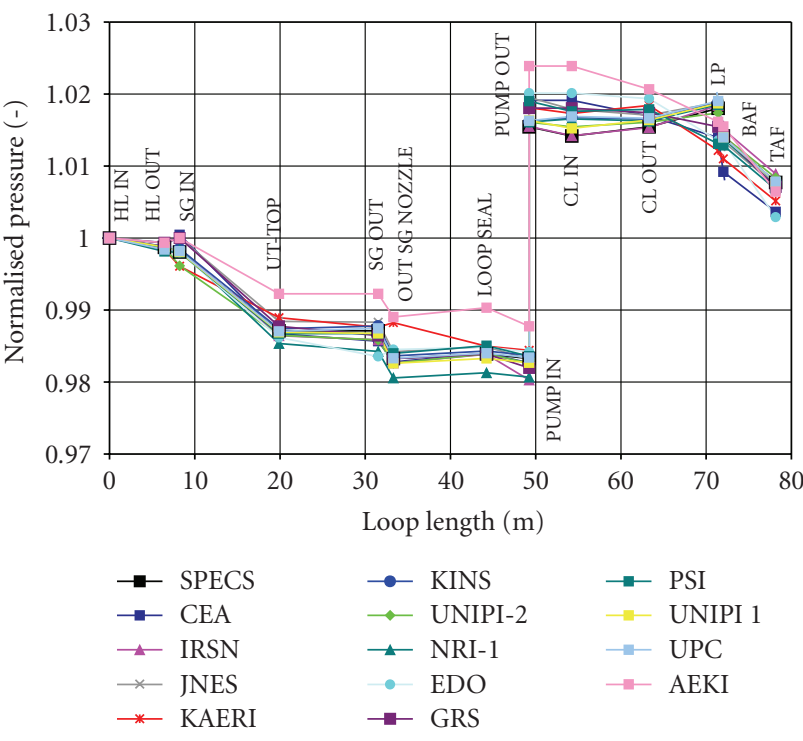

FIgURE 4: Normalized pressure curve along the loop.
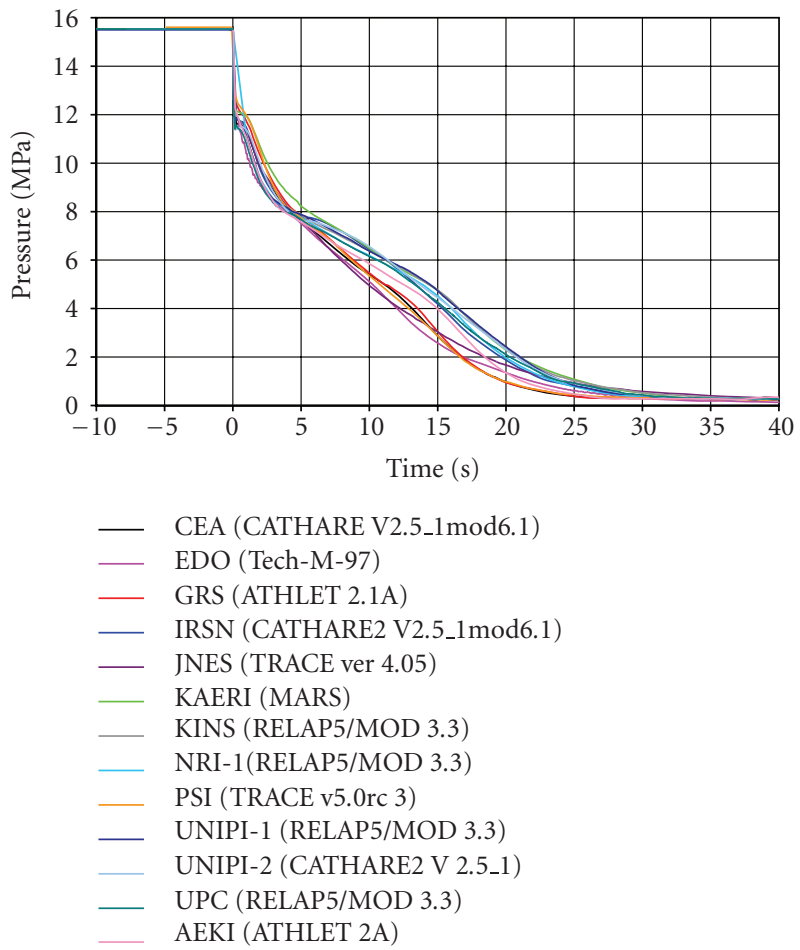

Figure 5: Time trends of intact loop 1 pressure in hot leg.

and fuel dimensions) and, among them, fuel conductivity, radial power factor (hot rod power), and fuel dimensions. The parameters in Figure 12 are the following: s1-fuel conductivity, s2-gap conductivity, s3-power after scram, s4power before scram, s5-hot rod power, s6-LPIS delay, s7accumulator liquid volume, s8-accumulator pressure, s9containment pressure, and s10-hot/cold conditions for pellet radius.
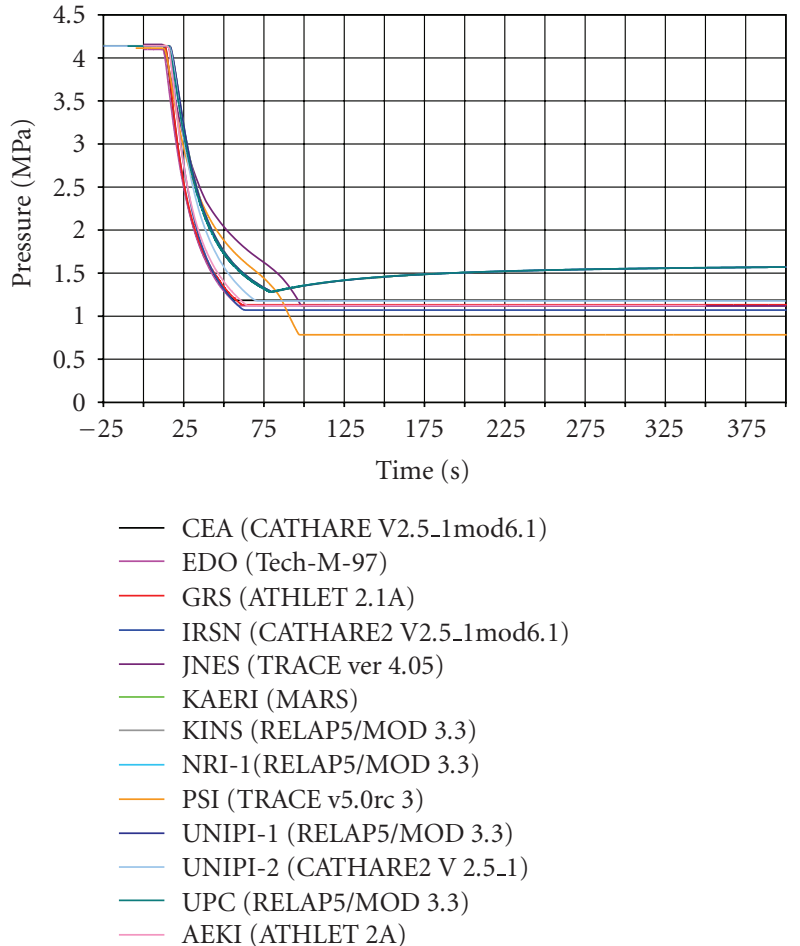

FIgURE 6: Time trends of accumulator 1 pressure.
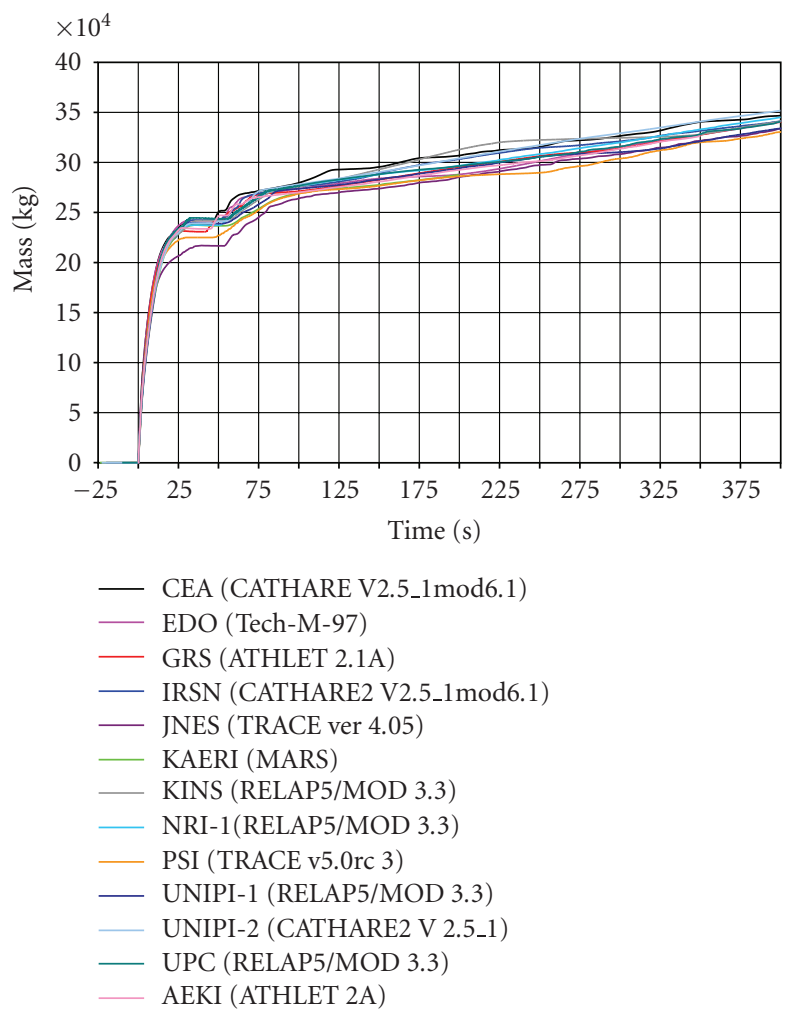

Figure 7: Time trends of integral break mass flow.

Regarding the $\triangle R E F L O O D$, the average participant has encountered that the parameters having more influence in the time of reflood are containment pressure, power after 


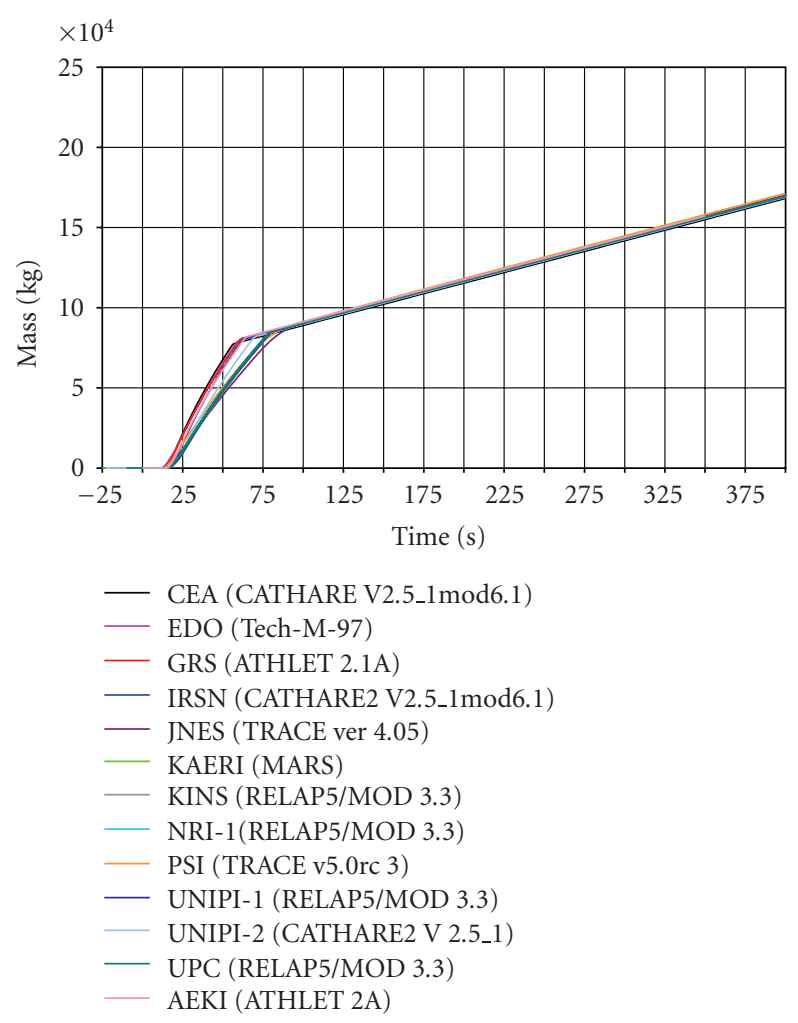

FIGURE 8: Time trends of ECCS integral mass flow.
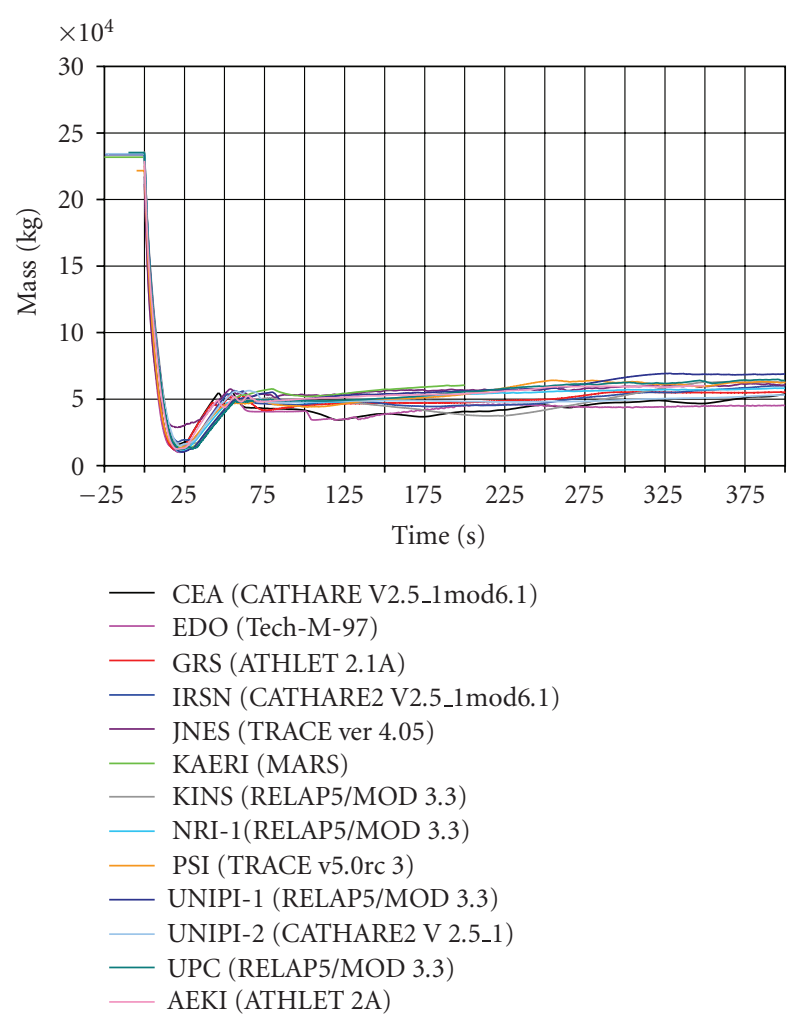

FIGURE 9: Time trends of primary system mass (including pressurizer).

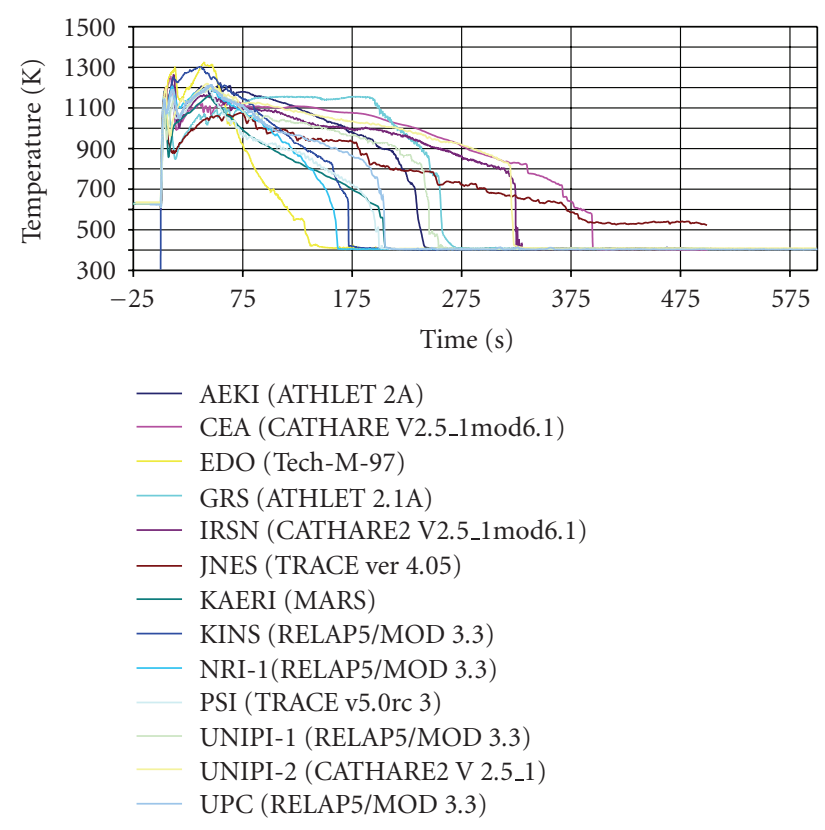

FIgURE 10: Time trends of maximum cladding temperature.

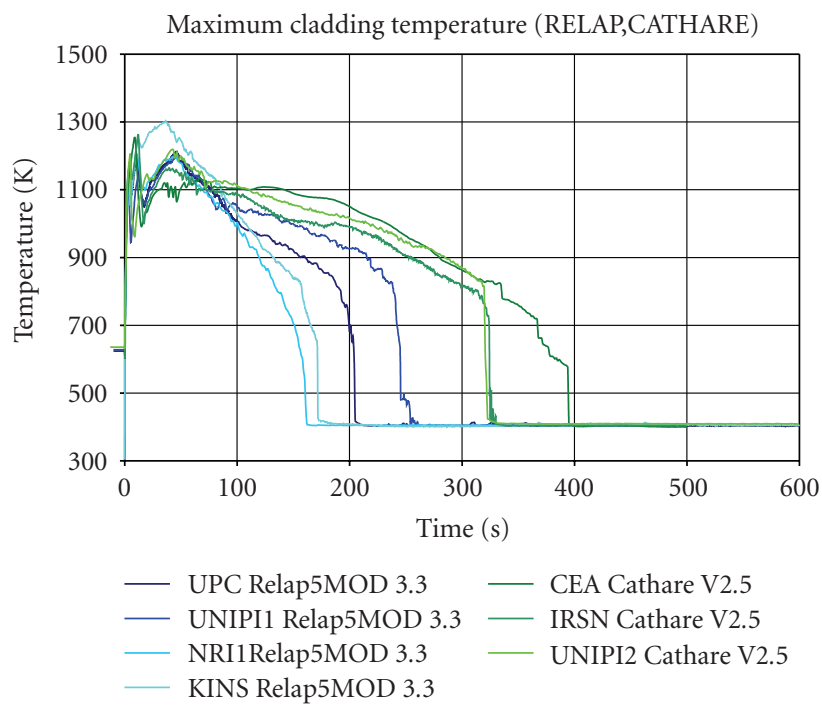

FIGURE 11: Calculated hot rod temperature/Code effect considerations.

scram (decay power), radial power factor (hot rod power), power before scram (steady state power), and volume of liquid in accumulators.

The sensitivity study performed in Phase IV has proved to be useful in order to set up the Specification for Phase V.

\section{Conclusions}

Conclusions can be summarized as follows:

(i) all participants managed to simulate the scenario and predict the main parameters with credible consistency; 


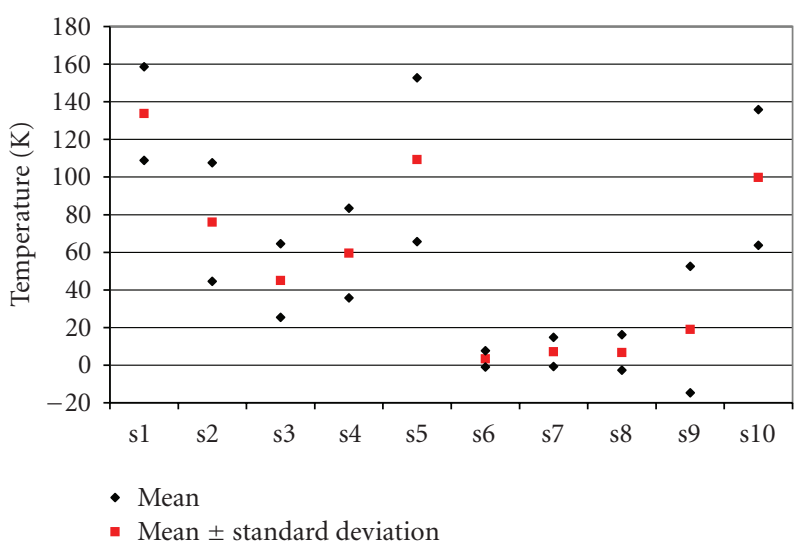

FIGURE 12: Sensitivities mean $\triangle \mathrm{PCT}$ values-Scalar parameters.

(ii) maximum values of PCT predicted by participants are quite close one each other;

(iii) PCT time trends and timing of complete core rewet still show some disagreements;

(iv) a database, including comparative tables and plots has been produced. This database is suitable for providing the explanations needed for the following phases.

About the announced difficulty of dealing with a plant that was in permanent shutdown condition from 1998, one can conclude that the participants in the exercise managed to work it out. Although no detailed information could be made available during the development of the project, the specification itself and further contacts among participants were sufficient to reach a suitable definition of common initial and boundary conditions.

The final calculation results had a credible consistency and are considered a good basis for the comparison work of next phase of the project, in which uncertainty bands will be calculated.

Phase IV results are a step forward that contributes to the general goals of BEMUSE project.

\section{Acronyms}

AEKI: Atomic Energy Research Institute

BE: Best estimate

BEMUSE: Best Estimate Methods plus Uncertainty and Sensitivity Evaluation

CCFL: Counter current flow limit

CEA: Commissariat à l'Energie Atomique

CSNI: Committee on the Safety of Nuclear Installations

DNB: Departure from nucleate boiling

ECCS: Emergency core cooling

EDO: $\quad$ EDO Guidropress

FA: $\quad$ Fuel assembly

GRS: Gesselschaft fäur Anlagen und

Reaktorsicherheit
HPIS: $\quad$ High-Pressure injection system

IRSN: Institut de Radioprotection et de Sûreté Nucléaire

ISP: International standard problem

JNES: $\quad$ Japan Nuclear Energy Safety

KAERI: Korea Atomic Energy Research Institute

KINS: $\quad$ Korean Institute of Nuclear Safety

LBLOCA: Large break loss of coolant accident

LOCA: Loss of coolant accident

LOFT: $\quad$ Loss of fluid test

LPIS: $\quad$ Low-pressure injection system

NEA: $\quad$ Nuclear Energy Agency

NPP: $\quad$ Nuclear Power Plant

NRI: $\quad$ Nuclear Research Institute

OECD: Organization for Economic Cooperation and Development

PCT: $\quad$ Peak cladding temperature

PSI: Paul Scherrer Institute

PWR: $\quad$ Pressurized water reactor

RTA: Relevant thermalhydraulic aspects

UNIPI: University of Pisa

UPC: $\quad$ Universitat Politècnica de Catalunya

WGAMA: Working Group on Accident

Management and Analysis

$\triangle$ PCT: $\quad$ Delta PCT

$\triangle$ REFLOOD: Delta time of reflood.

\section{Acknowledgments}

This paper contains results produced within an OECD-NEA BEMUSE Project. The authors are grateful to OECD-NEA. The authors are also grateful to the Spanish Nuclear Safety Council (Consejo de Seguridad Nuclear) for funding UPC's participation in the project.

\section{References}

[1] NUREG/CR-5249, "Quantifying Reactor Safety MarginsApplication of CSAU to a LBLOCA," December 1989.

[2] G. E. Wilson, et al., "Quantifying reactor safety margins—part 2: characterization of important contributors to uncertainty," Nuclear Engineering and Design, vol. 119, pp. 17-31, 1990.

[3] W. Wulff, et al., "Quantifying reactor safety margins-part 3: assessment and ranging of parameters," Nuclear Engineering and Design, vol. 119, pp. 33-65, 1990.

[4] "Best-Estimate Methods (Including Uncertainty Methods and Evaluation) Qualification and Application," First Meeting of the Programme Committee NEA/SEN/SIN/AMA(2003)8, Issy-lesMoulineaux, France, February 2003.

[5] M. Pérez,, F. Reventos, L. Batet, and R. Pericas, "Phase 4 of BEMUSE Programme: Simulation of a LB-LOCA in ZION Nuclear Power Plant. Input and Output Specifications," UPC Report, Barcelona, Spain, July 2007. 

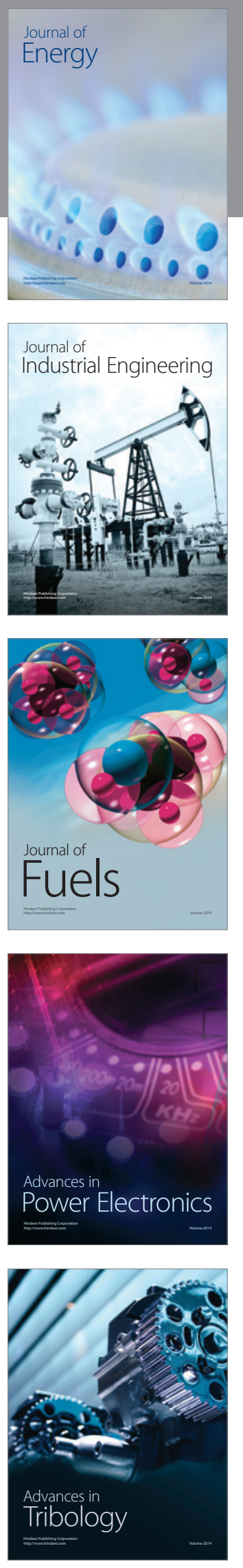
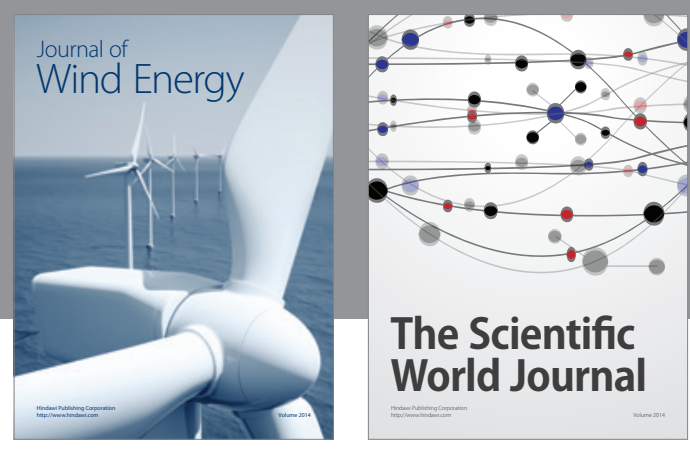

The Scientific World Journal

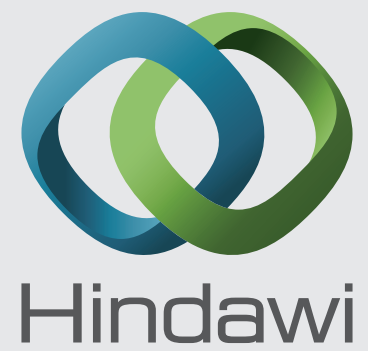

Submit your manuscripts at http://www.hindawi.com
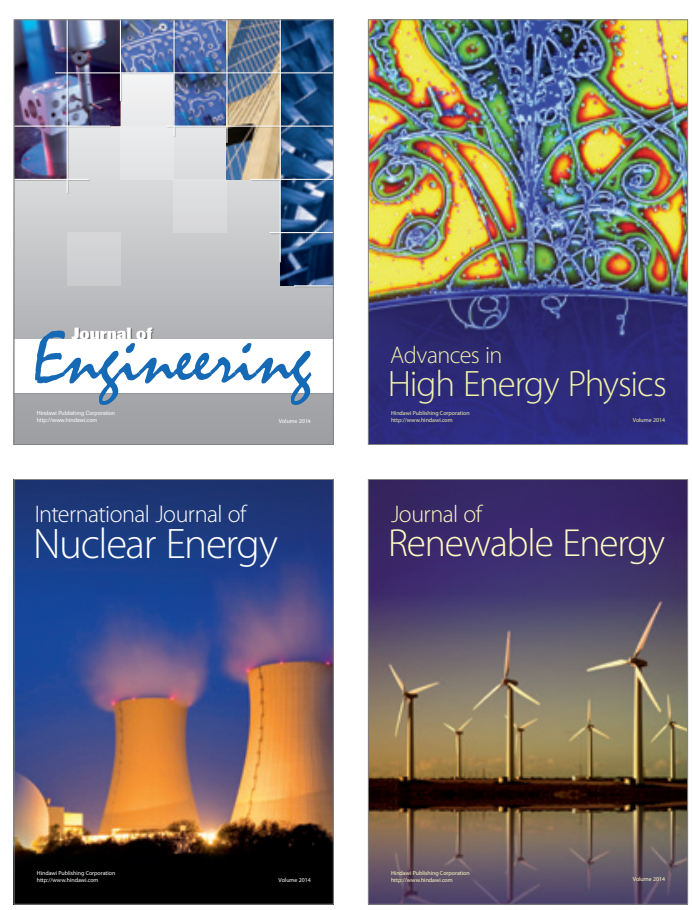

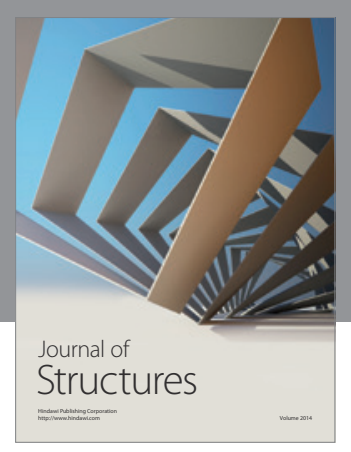

Rotating
Mechinery
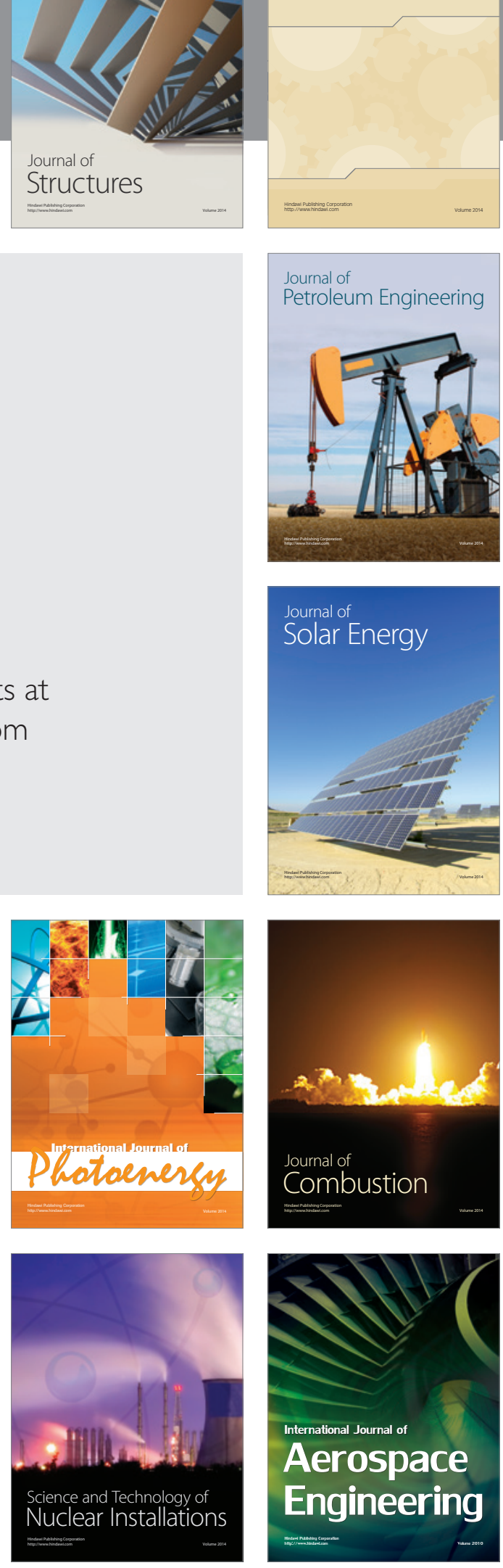